\title{
AWARENESS OF DEATH: A CONTROLLABLE PROCESS OR A TRAUMATIC EXPERIENCE?
}

\begin{abstract}
Argo Moor
We do not know what comes after death. But as human beings, aware of our mortality, we inevitably relate ourselves to our mortality. One output of such relating includes various beliefs about how the life of a person, his/her death and after-death existence are connected. Different beliefs have different ethical consequences and different impact on life. The beliefs do not have a direct influence, but they presume the actualisation of awareness of death.

This paper shall focus on the conditions of such actualisation and describes the accompanying phenomena. It is shown how, depending on environmental, cultural-ideological and personal qualities, people may become aware of death either in a relatively harmonic way or it may be a traumatic experience.
\end{abstract}

\section{THE CONCEPT OF AWARENESS OF DEATH}

Death-related beliefs is one of the best-survived fields of tradition, rich in associations and an interesting source of research as such. The subject of death is among the most widely treated fields in the humanities. There is an enormous and inconceivable amount of tantalogical, psychological, philosophical and religious-historical literature related with death. It can be quite confidently stated that death awareness as a phenomenon in the cultural space of Europe has usually been talked about in connection with a crisis situation (loss of a close person, learning of an incurable disease) or ageing.

The phenomenon of death is also interesting in the context of value regulation, i.e. how and to what extent the beliefs of death do influence our everyday life and choices.

The value-regulative influence may be broadly divided into two. One part accounts for specific beliefs about death: whether it is believed that death is the absolute end of the human existence or 
that death is followed by existence in the otherworld or reincarnation. Different beliefs bring about different ethical consequences. The other part is for death awareness as a phenomenon. A man may believe in the existence of heaven and hell, but in the case of non-actualised awareness of death, its real impact will be relatively modest.

Treatment of death awareness in the value-regulative context inevitably raises the need to treat it also in the framework of people's everyday life.

Death awareness may be situational or abstract. The first can be met in situations where there is actual danger to one's life. Such awareness presumes concrete or situational thinking. In the case of abstract awareness of death one may be aware of mortality, feeling good and safe. Such awareness presumes abstract thinking, which for a long time has been considered typical solely to human beings.

A human is aware of his/her death, but it is difficult to say if this is his/her monopoly or do higher animals possess similar awareness. Modern animal psychology has explained that the difference between humans and animals is smaller than it was believed earlier. Efforts to prove situational ability to think, followed by some elements of abstract thinking (ability to remember, longer reaction time) have produced convincing evidence that at least some higher animals have the ability of abstract thinking (see the film "Dolphin Dilemma" from the Great Book of Nature series). It may presumed that higher animals also possess abstract awareness of death. Whether it is really so, has not been proved yet, but there are numerous documented examples that allow to presume this. The mourning of wolves, but also elephants, dolphins and several species of apes after their loss of a partner is generally known.

The documentary "Why Dogs Laugh and Chimanzees Cry" describes how a dog sacrificed itself for a member of the family. On a dusty road the driver did not see a cyclist who had got stuck in the rut. The dog ran barking beside the car and then jumped under the wheels. The car stopped a few metres from the cyclist. 
Argo Moor

\section{COGNIZING THE THOUGHT OF DEATH}

But back to people. Abstract awareness of death is divided into the latent and actualised awareness. In the case of the latent awareness of death one is aware that all people die, but there is no direct knowledge of one's mortality. One rarely thinks of death, especially one's own death, because thinking of it is considered useless or even harmful. The thought of death and mortality is accepted in general, but one tries to disregard events that actualise these facts, and if it is not possible, to forget such events. In modern European culture the principled awareness of death is the predominant type and one of its characteristic features is that the fact of mortality does not elicit any emotions. It is just an abstract knowledge that we do not cognise in our daily life.

When a person cognises the impact of his/her mortality on his/her life, we can speak of the actualisation of awareness of death, and this is usually connected with definite situations or processes. In the following just a few of them are listed:

1. Natural lifestyle and harmony with nature actualises the person's awareness of death, because in the case of such a lifestyle the person constantly sees death around him/her, death is a daily and natural event (grass turning yellow, trees withering; the relationship between the beast and the prey, etc.). Living as part of nature, the person senses his/her mortality and the naturalness of it. People with natural lifestyle have more actualised awareness of death than people with urban lifestyle.

2. Most natural and usual is the actualisation of the awareness of death in connection with ageing. Usually it starts with the so-called midlife crisis, which culminates with children becoming independent and leaving home, also reaching the top in one's career, accompanied by the fear that in future everything can only degenerate. An important turning point is also retiring and the feeling of inferiority and uselessness that often accompanies it.

A significant role in the actualisation of death is played by changes in one's body-image. Body-image is one of the most important parts of a person's self-image. When the external look and physical ability change with age, the person must inevitably match it with his/ 
her general self-image. So it is usually the change in a person's body-image that makes him/her sense his/her ageing.

3. A person's awareness of death is also actualised by loneliness. In this respect it is not really important whether it is a real (the person lives spatially isolated from others) or psychological loneliness, which the person can also feel surrounded by other people.

4. Awareness of death is actualised by the death of a close person. The effect is the stronger, the more unexpected the death is, increasing particularly in the case of the death of a young person, or unnatural death caused by an accident or violence.

5. Awareness of death is also actualised by the break-up of close relationships, whereby it is stronger for the one who is abandoned, and weaker for the one who has. Similarly, a long-time forced separation from a close person acts in the same way, although the actualisation is usually weaker than in the case of death or broken relationships.

6. Also, the turning points of human life - the birth of a baby, moving into a new house, jubilee, marriage etc - may actualise the awareness of death. Sometimes it is connected with sensing the time scope (e.g. a jubilee), another time with a so-called emotional, stirring feeling, which may be constituted of different main components (tenderness, satisfaction, sadness, loneliness etc). This state of mind often involves seeing life in a considerably wider perspective (the so-called view from above). Such a change in perspective is also frequently sensed while saving people or, for instance, following rescue operations on television.

Such events do expand the person's limits of perceiving space and time, including the cognition of one's own life in a wider perspective. In this context the literary motive is very interesting, where death comes just at the moment the person has found something that makes his/her life perfect (a classical example would be Goethe's Faust, but also Uwe Berger's "Calamity or the Love of Paul Fleming", Rein Põder's "Duck Driver", Trygve Gulbranssen's “The Wind from the Mountains"). Here the issue is not just creating a dramatic effect, but a widespread human experience. The same motive also exists in folk tradition: to guarantee a long life for an item that was 
Argo Moor

made, they left a small detail unfinished. The same is in the legend of the Old Man of Ülemiste, who promises he will flood the city of Tallinn as soon as the city is completed.

7. People as beings with limited time have many choices at the beginning of life. Each choice that is made decreases the following options, until the person gets to a point where he/she has no choices and he/she will die. So the choices that a person makes, remember $\mathrm{him} /$ her of his/her time limits and actualise the awareness of death.

Great changes actualise the awareness of death primarily in the socalled transitional stages, when the person has left a situation (job, place of living, exchange of partner) and has not yet switched over to the new situation.

8. An accident that might have ended with death can actualise the person's awareness of death. This presumes that the risk situation lasted for a sufficiently long time, also it is important to emphasise the relativity of time in crisis situations. For example, one may sense in a car accident as if the event took place in slow motion. Even events that last but a very short time (a few seconds), may seem very long. As mentioned above, such accidents with other people, especially with close ones and acquaintances, have a similar effect.

9. Severe, and particularly incurable diseases strongly actualise the awareness of death of the sick person and his/her close ones. In the same context the long-time caring for gravely ill (dying) persons could be observed.

10. Fear for another. Already since Aristotle, two approaches have been opposed in ethics: the ethics of duty (what to do to live a decent life; Immanuel Kant could be regarded the classic of this approach) and utilitarianism (what to do to feel good; the classics of this theory are Jeremy Bentham and James Mill). Emmanuel Levinas (2000) made an end to this opposition in a radical way: leaving the self-centred ethical theories behind, he asked the question: what do I have to do to make others feel good? According to E. Levinas, reponsibility for another person proceeds from the fear for another person, primarily the fear of the person's death. At the same time, E. Levinas distinguished it from the usual fear for an- 
other person, as such fear lacks the self-centred measure - the fear for one's own well-being.

Fear for another person occurs more often with those who feel they have in some respect realised themselves. It may become evident in relatonships with close people, especially one's children, rarely in relationships with people in general. E. Levinas regards the fear for another person as the basis of sociality and charity.

11. To some degree, the awareness of death may also be activised by films, books, drama performances, etc., if they include situations that activate the awareness of death. These, however, usually have a short-term impact.

12. The awareness of death is also actualised by killing, whether in the war, hunting or another situation. Undoubtedly, homicide in this context actualises the awareness of death much more effectively than slaughtering an animal.

13. Unknown phenomena, which are experienced by quite a lot of people during their lifetime and which are difficult to explain from the aspect of the common worldview, may also actualise the awareness of death. As an example we could take a look at some phenomena from traditional Estonian death omens. It is considered a death omen, if a person hears somebody calling him/her by name, but in reality there is no one. Or one hears footsteps and when he/she goes to see, there is nobody, like in the following recollection (The memories here and below have been collected by the author): ${ }^{1}$

We were sitting in a large room, 18 people all in all. Suddenly we heard the front door of the house open and somebody coming in the hallway. I sent a boy to see who it was coming so late. He came back and said that there was no one. Everybody had clearly heard the footsteps (Tartu 1999).

Usually people eliminate experiences to which no satisfactory explanation can be found in the framework of their common worldview, but on the other hand, such experiences may make them expand or change their worldview.

As death is an unknown phenomenon to people, they tend to classify other unknown phenomena in the same field. However, un- 
Argo Moor

known phenomena are significantly differently interpreted by the ontological and gnoseological types of culture.

One of the main features of ontological culture is to accept things and phenomena, without knowing their reasons or knowing how to analyse them. We could say that in ontological culture the most important is to describe what is experienced and therefore in that system the influence of the unknown on actualisation of awareness of death is greater. Traditional cultures are ontological.

In gnoseological culture the main consideration is the reason. If a question cannot be answered from the standpoint of the existing worldview, elimination mechanisms will be activated - the person either changes the description of the phenomenon, until it matches his/her worldview, or denies the event completely. The modern European culture is a typical gnoseological culture.

14. Death visions are close to the previous. In a visionary state or more frequently, in a dream, a person may live through his/her death or meeting with the personification of his/her death. The more realistic and clear the vision or the dream and the higher is the emotional charge of it, the stronger is the effect of the vision. Here we could continue with a dream recorded at Jõgeva in 1994:

There is a funeral in my first love's house. The house is not in its actual place, but nearer to the main road-near the bus stop. I glance at the curtains - these are violetish, of a material heavier than silk. And I know that I must not look out of the window. I go to the curtains and tear them apart - with two hands. The view opens to the west. Behind the window there is an empty ploughed field in twilight. Then suddenly somebody is standing in the field. He is somehow strangely familiar, but I know I have never seen him. He reminds me of my grandfather's photo a bit, he was bald too. We look at each other, just like remembering something. Then suddenly the man's face becomes ghastly, his eyes change into saucer-size silver wheels and at the same time I feel a deep crampy wince in me. I know that he killed me with his glance and as I die I know that he could not have done anything to me, had I not looked at him. 
Similar visions often occur in shamans' visions. For instance, the Nganasan shaman Djukhade Kosterkin's vision he is killed twice: first his heart is cut out of his breast and boiled, secondly his head is cut off and his body is chopped into pieces (Popov 1936). In the vision of the Tuva shaman the motive of death is expressed through maggots devouring the body (Diakonova 1981). If the shaman experiences death in a vision during the initiation period, it expresses the change in his personality (Lintrop 1995).

Sometimes the actualisation of the awareness of death may be associated with quite strange situations - for example, the sleeping position.

When I was in the secondary school, I took care to avoid the sleeping position where hands are crossed on the stomach, the so-called dead-body position. This behaviour developed from my conviction that in the above-mentioned position I will die. The fixed idea that when I sleep with hands crossed, I might not live until morning, made me feel fear, anxiety. I remember situations when, having discovered myself sleeping in the 'dead' position, I woke up with a start and changed the position of hands at once. At the same time my attitude to this obsession was like to inevitability, although I could not cope with it completely. Now, sleeping in the mentioned position arouses interest in me, although the conviction has largely remained (Tartu 2001).

This story is interesting because in the religious system of traditional cultures it is often prescribed in which position or orientation one may or must not sleep. For example, the Nenets religion says that a person must sleep on his/her side, because if he would sleep on his/her back like the dead are lying, the God will not consider him/her alive nor protect him/her from death. In Nenets houses, the dead are also placed feet to the wall and head to the middle of the room, consequently live people should sleep, head to the wall (Lehtisalo 1924). Generally people do sleep, head to the wall, as this makes them feel more secure.

Undoubtedly, the above list of situations that actualise the awareness of death is not exhaustive, yet it should provide a sufficient overview of the situational character of the actualisation of the awareness of death. 
Argo Moor

\section{DEATH AND FEAR}

Cognition of death is psychically difficult for people, because it means meeting the main fears. According to Fritz Riemann, there are four main forms of fear: fear of the loss of identity, fear of loneliness, fear of the inevitable and fear of changes (Riemann 1994). We can observe the fear of death as the total of the four main fears, where the fear of the changes is cognised primarily as the fear of the unknown, often accompanied by the fear of pain. The above-listed situations contain all of these main human fears.

Subjectively, fear is an unpleasant feeling for people, they try to avoid contact with it - it is psychically easier not to remember one's mortality. Therefore, the actualisation of awareness of death presumes either some pressure from the surrounding environment in the form of situations that remind one of death or a strong ideological motivation. For example, being a samurai inevitably involves daily thinking of death, which helps one to create internal order and clarity. Also in Hinduism and Buddhism the awareness of one's own and others' mortality is regarded very important.

Pressure from the surrounding environment and ideological motivation as activators of the awareness of death are frequently interrelated - if the pressure from the environment is strong, the knowledge of death is usually also ideologically motivated. It is so in the religions of traditional nations, from the North American Indians to the West Siberian Khants and Mansis.

Actualisation of awareness of death presumes that an event is followed by the so-called after-time, during which the person's attention is not engaged in other activities. When the death of a close person falls to a very busy period of life, the actual actualisation may be postponed. When there is no such period of reflection for a longer time, the awareness of death may not be actualised and the death of a close person becomes an event that is suppressed in the subconscious. Such a suppressed event may emerge to the consciousness even after a longer period.

I was in a company of people and we all talked of people close to us. I started to talk of my late father, who had been close to me. I spoke a bit of my relationships with my father and reached the 
point how the message of his tragic death was delivered home to us. While talking, I thought I had overcome it a long time ago - it had been 7 years before. Meanwhile, much had changed in my life. After father's death I graduated from the secondary school and went to the university, moved to another place, got new friends. Yet while talking, suddenly as if everything returned again, I had a lump in my throat and I nearly burst in tears. I could hardly finish my story (Võnnu 1999).

The after-time is not needed in case the situation actualising the awareness of death lasts for a sufficiently long time and captures all attention (for example, in the case of shipwreck or an avalanche).

Several events and situations that actualise the awareness of death, also reduce its painfulness. Particularly the natural lifestyle should be emphasised in this context.

The more eventful the person's life has been, the less painful is the actualisation of awareness of death. On the other hand, it is typical to those who consider their life complicated. Naturally, actualisation of the awareness of death is easier at an older age after an eventful life; it is an independent phenomenon that accompanies ageing, after all. What also influences the nature of the awareness of death, is how satisfied the person is with his/her life, and also, how others in his/her opinion evaluate his/her life. Satisfaction with life and the supposedly positive evaluation reduce the painfulness of the actualisation.

Clinging to one's self-image will increase the painfulness of the actualisation of the awareness of death. People can be divided into those who try with utmost effort to preserve and secure their developed self-image, and those who do not consider it very important. The first ones are primarily characterised by their outwardoriented activity, they try to rearrange the world around them to make it match with their self-image. They usually have relatively firm value judgments, which are clearly divided on the scale of good and bad. The latter are characterised by a greater inwards-oriented activity, a relatively higher readiness to change themselves according to the changing environment and more relative value judgments. The fact that a person senses his/her death as the greatest change 
Argo Moor

in life, is an explanation to the difficulties of those people who are significantly oriented to preserving their self-image.

In this context, very important is the basic trust to the world, received in early childhood from mother. Those, whose trust to the world is greater, cognise death more painlessly. On one hand it results from the fact that they obviously are more trusting and open to different events, on the other hand they are less oriented to preserving their self-image. Trust to the world is also influenced by whether the person believes that the world as a whole and his/her own existence have some deeper objective and meaning (it is hard to have trust in the world, if the person does not think it makes any sense).

The preservation of a person's self-image has a cultural-ideological and environmental aspect. A person who constantly has to consider others' opinions and adapt to changing natural conditions, inevitably cannot be strongly oriented to preserving his/her self-image. Preservation of a person's fixed self-image is of little value in cultures, in whose value systems the extra-human absolute plays an important role. If that influence decreases, values become more relative, creating preconditions for evaluating the fixed self-image, because the different understandings of different people can be regarded as similarly correct. As the impact of common values and truths weakens, personal values and truths will actualise. This allows the orientation to the preservation of the fixed self-image to be evaluated much more widely.

Actualisation of the awareness of death is more painful and difficult, if the visions of death are dreadly and barely tolerable (hideous personifications of death, beliefs connected with dying and postmortem existence etc). The more the vision of death elicits the person's main fears, including the fear of pain, the more difficult is actualisation.

\section{VISIONS OF LIFE IN THE AFTERWORLD}

According to a traditional Estonian belief people continue their lives in the other world, in the so-called Toonela or the farm of Toone. Toonela looks quite like our world, except that it is dusky and the 
dead live there. In such a vision of death the fear of loneliness is largely eliminated, because in the land of the dead the people who died earlier are believed to be waiting. The fear of the inevitable remains, because you cannot avoid death. This, however, is alleviated by two circumstances: first, people also live in Toonela, therefore the pressure of the inevitable is not so great, and secondly, it was thought that there were several worlds for the dead, so that people could get to different worlds of the dead. They believed that there were seven heavens and seven hells, and there were separate beliefs about the dead who had not been buried according to the custom (Eisen 1920). As the afterworld and the person's activity and role there is believed to remain the same in the main part, the fear is naturally smaller.

All the main fears are reduced by the understanding of the interrelationships of the living and the dead, according to which the living and the dead belong together, despite living in different worlds. This belonging is expressed in the prayers and customs of sacrificing, which is directed to the dead, especially in the customs of the All Souls' period in November. Namely, the dead were believed to be among the living at certain ritualised times (festivals, especially the All Souls' period). People either called them home by name, or went to the cemetery, where they held a ritual feast.

According to Karl Jaspers, the fear of death is dual by nature: the fear of existential non-being (existentielles Nichtsein) and vital not being here (vitales Nichtdasein). The existential fear is deeper and can relativate the vital fear. Contact with knowledge of existential being is a source of peace and mental balance for a dying person. $\mathrm{K}$. Jaspers underlines that such knowledge of existence must rely on the communicational ability, which presumes the continuity of historical consciousness. Otherwise the empirical being becomes absolute and the person interprets existence as living at any cost. Thirst for life relativates the existential fear, destroys existence and brings along a confused fear of death (Jaspers 1956). Existential fear of death is essential and as such, cannot be overcome in some respects.

I prefer not to differentiate these two layers of fear. It can be believed that any person, actually facing the death, clearly perceives the different levels, but in everyday life we rarely sense this dual- 
Argo Moor

ity. This simplification is justified, because from the existentialist philosophy, common consciousness primarily accepts the concept of death as the absolute end, without really asking anything about the different levels of being. In this case there is fear of the total end and the maximum changes, which have no analogy with life situations. As mentioned above, in this case there is maximum fear of the inevitable, because everyone is mortal and presumably die similarly - death means an end to everyone.

We have also referred to the maximum fear of the loss of identity, because the total end also means the complete interruption of one's identity. Essentially there is no problem of loneliness, because there is no belief in continuity anyway. Which, of course, does not mean that the fear of loneliness would be solved. For such a death image loneliness is dreaded in the respect that one is completely isolated from the living. In the case of the vision of death as the complete end, an aspect of one of the main fears - the fear of changes - the fear of the unknown is amplified, because one lacks the vision of afterlife existence. The actualisation of the death awareness of a person, in whose vision death will end it all, is supposedly much more painful than of the person who believes in the farm of Toone. Different death visions allow a person to be more or less open to cognising death, as an ecent belonging to his/her life.

\section{DEATH OMENS}

The stereotypical picture of death today is a hideous-looking skeleton. Cognising death is likely to be painful for a person envisioning death according to this picture. In Sami beliefs there is a motive where a mythical elk reveals itself to the shaman for three times. First, when the shaman is young, for the second time, when he is in the prime of life, and for the third time, when he dies. This vision creates a mystical impression of death and makes the awareness of death less painful.

Equivalents to the above example can be found from quite different cultural context. For example, it is known from the biography of Karl Ernst von Baer, the embryologist, that in his childhood he had once seen a live peacock with spread back plumage. This experience had been so captivating for him that he forgot all about his 
surroundings. Later in his life Baer waited and searched for this experience to repeat: he wanted to see a live peacock with its back plumage spread like a fan. Yet the situation did not recur: either the tail was not spread or the peacock with the spread feathers was just a stuffed bird. Gradually the conviction grew in Baer that if he ever should meet a peacock with a spread tail again, it would be the herald of his death.

Although death (and death omens) have their stereotypical forms in different cultures, they are always strongly influenced by the psychological features of the perceiving individual. The forms sometimes have names that refer to the world of the dead (in Estonian for instance toonetikas for black woodpecker or toonekurg for the stork). Often death appears with a human face.

In an ontological culture the actualisation of the awareness of death is relatively easier, because several existential problems (what is death, what is the meaning of human life etc) are of secondary importance there. In principle, the existence of death may also be accepted without knowing what death is or why it is there.

On the other hand, in gnoseological culture the acceptance of death presumes precise knowledge about death. As such knowledge or beliefs are rarely clear-cut and completely cognised, it is difficult to accept the existence of death, which also makes the actualisation of the awareness of death more painful.

The painfulness of the actualisation of awareness of death also depends on whether the person has a predominantly cyclical or linear sense of time. The cyclical sense of time is earlier and natural in essence. There is no clear beginning or end; there is just an endless cycle of seasons. Human life is similarly cyclical: birth is followed by death, death by birth. In the religion of traditional nations there are often motives in which a person is reborn in the world a while after his/her death (or one of his/her souls is reincarnated).

According to M. Eliade, the linear sense of time arises in the desacralisation process of the cyclical sense of time. The desacralised cyclical time starts to harass the person, and to escape it, the cycle is interrupted and linearity is created. 
Argo Moor

In reality, people often live in both the linear and the cyclical time, the problem is rather, which of them is dominating. In modern European culture the linear time is dominating, expressing the strive for continuity in different social orders. Human life has a definite beginning in birth and a definite end in death. This treatment of time in itself does not offer people the possibility of reincarnation or the new start, which is the source of painfulness.

The painfulness of the actualisation of awareness of death is also increased by dichotomous thinking. Depending on the cultural context, the person may feel that the opposites make up the whole (the so-called Oriental thinking, where the tao is expressed in the opposition of yin and yang) or exclude each other (the typical Western thinking).

When man starts to perceive his time-limitedness, he feels there is not enough time. This involves moving from the continuous linear time, controlled and reproduced by social rhythms, into the personal temporal time with accelerations, decelerations and interruptions. Such an exit to the personal time decreases the connection of the person with the social value system.

For the sake of social stability it is important that both work and human relationships were highly valued. This means that a person should not doubt the meaning of his/her social role as a worker and a citizen. This is supported by the illusion of continuity. Against the background of the actualised awareness of death both human relationships and work (in its wider meaning) inevitably acquire a temporary nature, because nobody knows his/her time of death. Perceiving the temporariness of relationships and works always raises the question of their reasonableness, so reducing in its turn the person's connection with the social value system. Figuratively speaking, it is like renovating a room, which you know you may have to move out of tomorrow.

\section{REACTIONS TO AWARENESS OF DEATH}

One of the most powerful reactions to the actualisation of the awareness of death is the opinion that death does not exist in reality. According to Uku Masing, the Estonian historian of religion, death 
is a psychosis of the mankind. This refers to the belief that people die because they believe in the existence of death.

Although such a response may at first glance seem irrational and even absurd from the ideological aspect, yet it is natural. On the one hand people have a real experience of their being alive - they have a kinetic body to act, they have feelings and thoughts and they cognise their existence. At the same time they are aware of their mortality. As the awareness of death actualises, there is an increasing opposition between the two poles, and the opposition is primarily expressed by a vigorous denial of the existence of death.

Similar syndrome sometimes also occurs with people who feel well, but at the same time know they are incurably ill (for instance, HIVpositive persons). Which of these responses are revealed and in which order they reveal in a specific person, depends on the person's internal orientation and the situation, in which the person is at the time the awareness of death actualises. For example, people who are strongly oriented to personal career are likely to reassess their works and people who have high achievement needs may develop a feeling of time-limitedness. People who are attached to their close ones are likely to reassess human relationships.

The change in the value orientation caused by the actualisation of the awareness of death may be described as a three-stage process. In the first stage the awareness of death has not actualised and the person strongly identifies with the widespread social value orientation. In the second stage death actualises, the world is perceived in a more self-centred way. Connection with the social value orientation decreases and personal interests emerge, often opposing the social interests. In the last stage the social and personal interests are reconciled. Personal self-realisation is placed into a context where it also benefits for others. Such search for balance between one's personal and social interests is universal and does not belong to the awareness of death only, but to all situations in which personal interests clearly emerge. 
Argo Moor

\section{DYING AS A PROCESS}

In tantalogical and psychological literature several different phases of dying are described. In the interests of analogy and background, let us list some of them. Dying is not just a biological process, but according to A. Weisman undergoes the phases of biodynamic, sociodynamic and psychodynamic regression (Weisman 1961). In the opinion of A. Weisman death is before the person in the impersonal, statistical, interpersonal (thoughts of how my death affects my kin) and intrapersonal (expressed in the effort to preserve one's identity even when dying) meaning. So, for different people the "centre of gravity" of dying is in different phases (Weisman 1961).

Elisabeth Küber-Ross points out five stages: rejection, anger, bargaining, depression and accepting (Küber-Ross 1969). U. Qvarnström distinguishes mature and immature rejection mechanisms depending on the person's age: children have illusory imaginations, adults sublimation, humour etc. U. Qvanström underlines that immature rejection mechanisms can continue all through the person's life, expressed for example in fantasies or passive aggressiveness (Qvanström 1993). At the same time it is emphasised that the process of dying is individual by nature, typification into phases is just a generalisation.

Here we should briefly stop at feelings as one possibility to typify the process of accepting one's own mortality. In the actualisation process the fact of one's mortality brings forth fear, anger, sense of guilt, sadness. Through these feelings a person moves from denying his/her own death to accepting it. So, substantially it is a typical mourning process, differing only in that we are used to seeing mourning always in connection with someone else, be it his/her death or separation from him/her. Actualisation of the awareness of death also makes us mourn, only now the cause is the mortality of ourselves. In the case of mourning one may stick to certain phases of mourning, the same occurs in the case of mourning caused by one's own mortality. The complete experience of mourning must lead to the complete acceptance of the event that caused the grief, agreement with the event. This presumes understanding of one's feelings and skills and trust to express one's feelings. 
Sticking to the phase of fear is caused by the person thinking that he/she must be brave and capable and not acknowledging his/her fears, not to speak of finding solutions to them. Another reason for sticking to the phase of fear may be the fact that fear as a feeling is often subjectively unpleasant to the person and he/she does not wish to experience it. So, for undergoing the mourning it is important to be open to different feelings, even to those that are subjectively unpleasant. The mourning, often very long and troublesome, and sticking to some phase of mourning may be due to the human tendency to strive for the so-called good emotions (joy, tenderness, satisfaction etc) and avoid bad feelings (anger, sadness, envy etc). According to this orientation, the so-called good feelings could be regarded the person's objectives. It is regrettable that such treatment of emotions, superficial and wrong from the psychological aspect, is spread even in psychological counselling and literature oriented to a wider audience. Naturally, such orientation is reproduced in large numbers by different entertainment books and films.

\section{LONGING FOR DEATH AS A DRIVE FOR PEACE}

According to Sigmund Freud, man's deepest drive is an irrational drive for peace. This does not care for pleasures or pain and often exceeds even survival needs. As the primary expression of this drive, a person creates the general orientation, with the help of which he/ she describes the world. On the level of feelings, harmony with this drive means similar openness to all feelings. So, there are just feelings, which the person is used to and can handle and feelings, which he/she cannot handle and which are therefore assessed as negative.

Undergoing the grief over one's mortality and acceptance of one's mortality are also made more complicated because of the abovelisted reasons, which make the actualisation of the awareness of death hard and painful. In this context we should enlarge on the understanding of death, widespread in secular-existentialist philosophy and psychiatry. According to this idea, the person wishes to find his/her place in the world and the reason for his/her existence. At the same time, he/she cannot cope with it, nor can he/she perceive the world as a whole or his/her place or role in it. So, the person 
Argo Moor

has to create a personal meaning for his/her life. While it is believed that death is the end of the whole human existence, death will also destroy the personal meaning the person has given his/her life. So he/she has to live, facing the absurd, live as if life had a meaning, yet knowing that death will destroy it. According to Martin Heidegger, fundamental is the relationship with death, where everything that is non-authentic in relation to the other is cancelled, because one always dies alone (Heidegger 1927). Under the influence of this context the fear of death is seen as a main fear. According to this way of thought, the deeper reason for the fear of loneliness or making decisions is the fear of death, which is made practically insuperable - it is the fear of something unknown, at the same time total and inevitable and as such, incomprehensible for or very hard to comprehend by the person.

If we divide the fear of death into the fear of loneliness and the fear of loss of identity, the person will not meet a great fear, but many smaller ones and there is a real possibility to overcome them. This will also make the mourning process faster and more harmonic.

Acceptance of denial, fear, anger, guilt and sadness - this is the most usual order of mourning stages. Of course, they need not occur in this fixed linear sequence. In some cases, anger may reveal immediately when the awareness of death is actualised, yet, for instance, it does not eliminate the emergence of anger later on. Often the phase of guilt is completely absent. The sequence of mourning phases is obviously dependent on situational factors, which underlie the awareness of death and the psychological qualities of the individual. Thereby it is important, how the person's awareness of death developed in his/her early childhood.

Together with the ability of abstract thinking, the child also develops an abstract awareness of death. The child understands that once his/her parents will die and he/she will die, like all people do. By the age of six or seven the child's awareness of death has been developed in general lines, whereas the child understands death as final separation from parents or people who take care of him/her. Also in children's death-related fears it is just the fear of loneliness that is dominant. In early childhood the person's awareness of death actualises for the first time and activates a mourning process, but due to several reasons, children usually do not reach the accept- 
ance of their own mortality. In the first place, children's mourning is by nature more related with the mortality of others and less with that of themselves. Secondly, a child, whose psyche and self-consciousness have not fully developed yet, cannot be expected to undergo the mourning process independently. Thirdly, parents try to prevent the child from getting hurt and so make the experience of the mourning phases impossible. Fourthly, children inevitably take over the attitudes of people around him/her. Today's European culture, however, could be provisionally called the culture of forgetting death, because the majority of its members only possess the latent awareness of death.

The time, within which we can reach through the different phases of mourning from the denial of our mortality to its acceptance, may extend over several years. Usually it takes at least two months and is dependent on the intenseness of mourning. The more intensive is mourning, the less time it takes to accept one's own mortality. In some specific cases, for example accidents, it may occur very quickly. When a person escapes from a sinking ship, having lost the hope of escape at a certain moment he/she will accept his/her death after undergoing very intensive phases of mourning. If such a person is saved, he/she may have accepted his/her mortality.

But important is also the other association. People who have reached acceptance of their own death, also undergo mourning for others much more quickly and manage the above-mentioned main fears more easily.

Separately we should deal with the longing for death, which may reveal in connection with suffering (diseases, break-up of relationships and situations that activate the awareness of death). Prolonged suffering creates a strong need to get free of them and sometimes death is seen as the possibility to end the suffering. Suffering and the related longing for death may drive a person to suicide. As the latter is an event that greatly destabilises the close ones and more broadly, the whole society, it has usually been condemned. The general disapproval of suicide and the denying attitude to death has created a situation in the European cultural context that the longing for death is regarded an abnormal or sick feeling. This is accepted only for old and ill people. 
Argo Moor

Old people's longing for death often increases in connection with changes in the person's social atomic structure (the person with relationships important for him/her). When a close person is lost it is normal that in the mourning process psychic energy is released, which connected the mourner with the dead person, and on account of the released energy new close relationships can be created. However, people's adaptability decreases with age, resulting in a situation in which older people leave the relationships with the dead unbroken. So in time quite specific social atomic structures may develop, in which there are more relationships with the dead than with the living. This can also be expressed in sayings like "See, all my friends and people I know are dead already, I alone have remained, why doesn't death come already". Such situations are quite usual in remote villages, where most people of the working age have left for the city, so that the average age of the villagers may be more than seventy years. From the aspect of the person's social atom it could be said that in reality, these people already live in the afterworld.

However, if a person gets in different psychotherapeutic experiences (for example, to write his/her own funeral speech, make a will or imitate his/her personal funeral etc), it will becomes evident that in such situations many different feelings are experienced: sadness, peace, love, fear, indifference, but very often also longing. As far as one has not had personal contacts with death situations, it is considered natural that death is scaring, a general abstract attitude of denial rules. When personal contacts arise, such denial is replaced by definite emotions, whereby the fear of death is often balanced by the longing for death.

Death is one of the first and most evident of the unknown experiences for people - the living have no experience of death. Naturally, everything unknown generates fear in us, and on the other hand, is of interest. So the longing for death may be observed as an expression of interest in something unknown and the existence of it as an important component of mental health.

Longing for death in this form may reveal in emotional contacts with the infinity: the boundless blue sky, innumerable stars in the sky, the inconceivable expanse of landscape etc. So, the longing for death is a primary emotional force, which enables the person to 
have a cognised and at the same time harmonic contact with his/ her own mortality.

Longing for death considerably facilitates the actualisation of the awareness of death, whereby the acceptance of death does not have to be a dramatic experience of mourning, but the interest balances the fear and one's own mortality is accepted quite painlessly. In this aspect, the problem is rather whether and how much modern people find situations in the European death-denying culture, which enable them to study their own personal and definite relationship with death without being limited by the "decisive condemn of decent people".

\section{SYMBOLIC SURPASSING OF DEATH}

In this context also the ways of symbolically surpassing the death should be briefly dealt with. In the case of people who have not yet accepted their death, the ways of symbolically surpassing the death primarily play the role of denial of death. For those who accept their own mortality, they are rather added value, through which life is seen in a wider scope.

1. Death is surpassed through children, descendants. Parents believe in living further in their children.

2. Death is surpassed through creation (works). People often wish that after his/her death something would remain that was made by him/herself, be it a book, film, house or an item.

3. Death is surpassed by the so-called eternal nature. People believe themselves to last as material particles in nature's food chain; their body is food for plants, but also for insects - for new life.

4. Death is surpassed through memory. It is emphasised that although the person dies, he/she will not be lost, but lives on in the memories of the living.

In this context it is not correct to treat the so-called mythological way, in which the person hopes for either reincarnation or further life in some other world, as a symbolic way of surpassing death. 
Argo Moor

Undoubtedly, such lines of thought provide consolation, but they can be regarded as symbolic ways of surpassing death only proceeding from the question what death is. As the living have no experience of death, the belief that death is the final end of human existence is not more motivated than the belief in reincarnation or the existence of afterworld(s). The formation of it subjects to analysis similarly to other beliefs.

\section{References}

Diakonova, Vera 1981. Tuviiskie shamany i ikh sotsialnaia roll v obshtshestve. Vdovin, Innokenti (ed.) Problemy istorii obshtshestvennovo sosnania aborigenov Sibiri. Leningrad: Nauka.

Eisen, Matthias Johann 1920. Eesti mütoloogia [Estonian Mythology] 2. Tallinn: Rahvaülikool.

Heidegger, Martin 1927. Sein und Zeit 1. Jahrbuch für Philosophie und phänomenologische Forschung, 7. Halle: Niemeyer.

Jaspers, Karl 1956. Existenzerhellung. Philosophie 2. 3. Aufl. Berlin \& Göttingen \& Heidelberg: Springer.

Küber-Ross, Elisabeth 1969. On Death and Dying. New York: MacMillan. Levinas, Emmanuel 2000. Entre nous: on thinking-of-the-other. London: Athlone Press.

Lintrop, Aado 1995. Šamaaniraamat [The Shaman Book]. Tartu: Ilmamaa.

Lehtisalo, Toivo 1924. Jurakkisamojedien vainajainpalvonta. Kalevalaseuran vuosikirja 4. Helsinki: Söderström.

Popov, Aleksandr 1936. Tavgiitsy. Trudy Instituta antropologii i etnografii. I, 5th edition. Moscow \& Leningrad: Institut antropologii i etnografii.

Qvarnström, Ulla 1993. Var död. Stockholm: Liber AB.

Riemann, Fritz 1995. Hirmu põhivormid: Süvapsühholoogiline uurimus [The Main Forms of Fear]. Tartu: Johannes Esto Ühing.

Weisman, Avrey D. 1961. Predilection to death: Death and Dying as a Psychiatric Problem. Psychosomatic Medicine, 23. 